\title{
Imaging Large Iron-Oxide Nanoparticle Clusters by Field-Dependent Magnetic Force Microscopy
}

\author{
Christian lacovita, Roxana Dudric, Mircea Vomir, Ovidiu Ersen, Bertrand Donnio, Jean-Louis \\ Gallani, and Mircea V. Rastei*
}

Cite as J. Phys. Chem. C 2021, 125, 43, 24001-24010

Publication Date: October 21, 2021

https://doi-org.scd-rproxy.u-strasbg.fr/10.1021/acs.jpcc.1c05426

\begin{abstract}
Iron-oxide nanoparticles are intensively considered for high-performance biomedical applications, where simultaneous functionalities, such as magnetic state, large surface area for maximal protein/enzyme binding, high magnetization values to provide large signals, and good dispersion in liquid media, are usually required. In this context, the association of individual nanoparticles into large clusters is of particular interest. Here, we present a magnetic force microscopy (MFM) approach capable to image individual nanoparticulate clusters as large as $350 \mathrm{~nm}$ at room temperature and under variable magnetic fields. It is shown that an in situ removal of electrostatic interactions-particularly important for large particle sizes supported by dielectric substrates-in MFM experiments based on phase detection allows us to image the magnetic state of

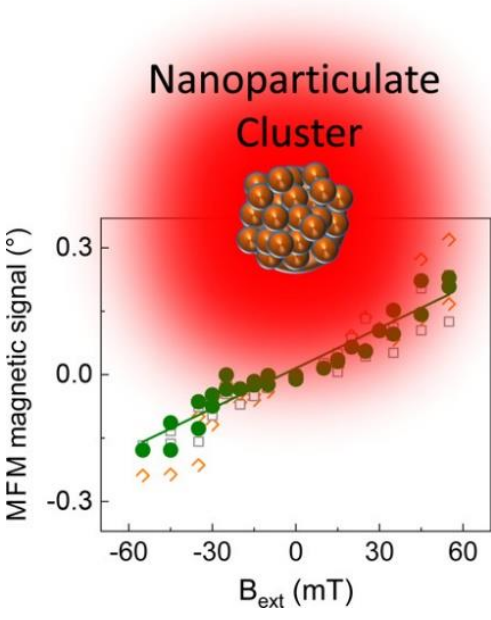
individual clusters. After taking into account the magnetization behavior of the microscope tip, the phase signal reveals a gradual and uniform rotation of the magnetization with the magnetic field and the absence of a hysteretic behavior for all investigated clusters.
\end{abstract}

\section{Introduction}

Various applications in bio-nanomedicine, (1-3) bio-separation, $(4,5)$ drug delivery, (6-8) magnetic hyperthermia, (19-11) magnetic resonance, $\underline{11-13)}$ or magnetic resonance imaging, $\underline{(14,15)}$ rely on the magnetic state of iron-oxide nanoparticles (NPs). (16-18) Generally, iron-oxide NPs display small magnetic moments triggering weak magnetic responses in magnetic fields, a drawback for their potential use in applications. $(19,20)$ A way to overcome this limitation is to enhance the magnetic moment by increasing the particle size. (21-25) One particularly promising solution is the formation of porous or nanoparticulate clusters by self-assembling or self-aggregation. (26-30) Hence, internanoparticle interactions within the clusters and the collective behavior can activate higher magnetic moments, (31-34) enhancing the magnetic responses while providing larger surface areas for binding functional biomolecules, as needed for instance in drug delivery. (35) 
Clusters made of NPs can be formed in a two-step process, including first the synthesis of the NPs and then their assembling through colloidal (solvo-phobic) interactions mediated by ligands. (36) The method allows tuning the NP interactions with a good control. Alternatively, a clustering process can be produced through a direct aggregation of NPs during synthesis. $(37,38)$ The polyol method has extensively been used in the last decade for this purpose. $(39,40)$ Its versatility enables the formation of different types of aggregates with controlled morphologies ranging from nanoclusters to nanoflowers and hollow spheres. (41-48) The major inconvenience of this method when applied for mass production is however the long reaction time ( $6 \mathrm{~h}$ to $24 \mathrm{~h}$ or even more). It has been shown that increasing the synthesis temperature above the boiling point of the polyols reduces the reaction time down to $1 \mathrm{~h}$. (49) Such a temperature rise also triggers the development of ferromagnetic atomic crystal phases $(\underline{50)}$ requiring systematic magnetic investigations.

A good understanding of the magnetic state of clusters made from NPs can be obtained by monitoring the collective magnetic response with superconducting quantum interference devices (SQUID) (51) or vibrating sample (VSM) magnetometers. (52) Such magnetic measurements performed on dried powders or colloidal suspensions are necessary for optimizing the chemical synthesis, as well as for concluding about the magnetic state. MFM (53) on the other hand is a technique able to image individual clusters and to address their magnetization states at the nanometer scale. (54-57) This technique has been used for revealing magnetic properties of individual NPs (58-61) and of magnetically correlated grain systems. (62) Nevertheless, MFM has also the potential to qualitatively investigate the magnetization state of clusters made of several NPs, in addition to their morphology, size characteristics, and separation. $(63,64)$ Moreover, in some cases, the magnetic interaction forces measured by the microscope can also be used for quantitative magnetization studies under magnetic fields. $\underline{(65,66)}$

Here, we present a MFM study on individual large iron-oxide nanoparticle clusters by operating the microscope under a variable magnetic field. The aim is to develop a microscopy method capable to address the magnetization behavior of individual clusters, without the adverse impact of electrostatic fields. In particular, the goal of this study is to demonstrate that individual clusters display a SP behavior at room temperature with specific MFM imaging characteristics. The study is realized on individual clusters with diameters of the order of $300 \mathrm{~nm}$. They are composed of crystalline nanoparticles of about $14 \mathrm{~nm}$. The clusters were deposited on a non-magnetic carbon-membrane grid (as used in electron microscopy). This allows the investigation of the same clusters by TEM and MFM, using a nanometric correlative approach. In particular, it will be shown that field-dependent (FD) MFM signals acquired after an in situ removal of electrostatic contributions can inform about the magnetization state of individual clusters as large as several hundreds of nanometres. In the limit of the magnetic fields used in the present study, the hysteresis loops indicate a superparamagnetic (SP) state for all investigated clusters.

\section{Experimental Details}

Synthesis The synthesis of magnetic clusters has been performed with the following products: iron(III)chloride hexahydrate $\left(\mathrm{FeCl}_{3} 6 \mathrm{H}_{2} \mathrm{O}\right)$ (Roth, $\geq 98 \%$ ), ethylene glycol (EG) (Roth, $\geq 99 \%$ ), polyethylene glycol 1000 (PEG1000) (Roth, $\geq 99 \%$ ), and sodium acetate trihydrate ( $\mathrm{NaAc}$ (Roth, $\geq$ 99.5\%). Iron oxide NPs have been synthesized according to the following procedure: $\mathrm{FeCl}_{3} \cdot 6 \mathrm{H}_{2} \mathrm{O}(0.27$ $\mathrm{g}), \mathrm{NaAc}(1.2 \mathrm{~g})$, and PEG1000 (0.5 g) were mixed and dissolved in $40 \mathrm{~mL}$ of EG. The solution was stirred at room temperature for $30 \mathrm{~min}$ and then transferred in a $60 \mathrm{~mL}$ round-bottom flask. Prior to sealing the reaction vessel, the solution was degassed with a flux of nitrogen gas for $5 \mathrm{~min}$. The solution was 
heated to $300^{\circ} \mathrm{C}$ with a constant heating rate of $5^{\circ} \mathrm{C} / \mathrm{min}$ and kept at this temperature for $1 \mathrm{~h}$. A series of multiple ultrasonication/magnetic separation cycles, in order to remove the excess of ligands and unreacted precursors, were applied. The increase of the temperature at $300{ }^{\circ} \mathrm{C}$ during the synthesis, which is well above the boiling point of $E G\left(200^{\circ} \mathrm{C}\right)$, enables the formation of iron-oxide clusters in only $1 \mathrm{~h}$, as compared to previous synthesis which require longer reaction times. $(41,42)$ As shown in the inset of Figure 1 and Figure S1a, the resulting iron-oxide clusters exhibit on average a spherical-like shape with diameters in the range of hundreds of nanometers

Methods TEM was carried out on a JEOL-2100F microscope working at $200 \mathrm{kV}$. A $5 \mu \mathrm{L}$ drop of an aqueous solution containing clusters was deposited on a copper grid covered with a carbon membrane. XRD measurements (Figure 1a) were carried out on powder with a Bruker D8 ADVANCE diffractometer, using $\mathrm{Cu}$ Ka radiation. Magnetic measurements (Figure $1 \mathrm{~b}$ ) were performed on powder in magnetic fields up to $2 \mathrm{~T}$, using a VSM. Atomic force microscopy (AFM) and MFM experiments have been performed in ambient conditions by means of a modified ICON-AFM apparatus controlled by Nanoscope $V$ electronics from Bruker. Low magnetic moment probes (PPP-MFMR-NanoSensors) with a coercive field of $25 \mathrm{mT}$ were used. Prior to the experiments, the analyzed clusters were not exposed to any magnetic field. The spring constant of the cantilevers was between 2 and $3 \mathrm{~N} \mathrm{~m}^{-1}$, and their resonance quality factor ranged between 500 and 1000. The magnetic field, normal to the substrate plane, was given by a home-built electromagnet, calibrated with a Hall probe.

\section{Results and Discussion}

Figure 1c shows three clusters which have been individually analyzed by both TEM and MFM. The isolated upper cluster, labeled S, has a diameter of $350 \mathrm{~nm}$, while the lower two clusters, labeled C1 and C2, have sizes of about 280 and $330 \mathrm{~nm}$, respectively. The mean crystalline size inside the clusters (Figure 1d), calculated using Scherrer's equation and a fit of the (220), (311), and (440) diffraction peaks, is around $14 \mathrm{~nm}$, indicating a multicore structure of the clusters. Moreover, the XRD pattern confirms the presence of a pure inverse spinel crystalline phase ascribed to magnetite- $-\mathrm{Fe}_{3} \mathrm{O}_{4}$ (PDF no: 88-0315 (67)), as can also be seen in Figure 1e. In addition, the corresponding atomic lattice parameter is very close to that of bulk magnetite $(a=0.8375 \mathrm{~nm})$. As shown by EDX analysis [Figure $1 \mathrm{f}-\mathrm{h}$ ], the iron $(\mathrm{Fe})$ and oxygen $(\mathrm{O})$ elements within the clusters are homogenously distributed.

At $4 \mathrm{~K}$, the VSM hysteresis loop [Figure 1b] measured on powders shows a ferromagnetic character with a saturation magnetization of $78 \mathrm{emu} / \mathrm{g}$, a remnant magnetization of $20 \mathrm{emu} / \mathrm{g}$, and a coercive field of $28 \mathrm{mT}$. At $300 \mathrm{~K}$, the saturation magnetization decreases considerably to $62 \mathrm{emu} / \mathrm{g}$, owing to spin-canting effects. (68) The remnant magnetization is of about $6 \mathrm{emu} / \mathrm{g}$ with a coercive field of 10 $\mathrm{mT}$, which suggests the presence of ferromagnetic phases.

The collective magnetic properties of the clusters have been further addressed by temperature dependences of magnetization (Figure S1c). From zero-field cooling (ZFC) curve, the onset of the ferromagnetic to SP transition (blocking temperature $T_{B}$ ) can be identified around $175 \mathrm{~K}$. However, the peak in the ZFC curve is very broad extending above $300 \mathrm{~K}$. This indicates a gradual transition to the SP state which is not completed at $300 \mathrm{~K}$ as the ZFC curve displays a magnetization value of $35 \mathrm{emu} / \mathrm{g}$. The field cooled $(\mathrm{FC})$ curve coincides with ZFC curve in a very short temperature range from 300 to 280 $\mathrm{K}$, which represents the so-called irreversibility temperature $\left(T_{\mathrm{IRR}}\right)$, while below $280 \mathrm{~K}$, it reaches a plateau. It is worth noticing that for monodispersed and non-interacting single-domain magnetic nanoparticles, the $T_{\text {IRR }}$ coincides with $T_{B}$ forming a narrow ZFC peak, with both ZFC and FC curves decreasing progressively toward zero, becoming even negative in the vicinity of room temperature. 
(69) For our samples, the behavior of ZFC and FC curves is therefore typical for an assembly of nanoparticles with a non-negligible distribution in the magnetic properties. This might be induced by interparticle interactions and/or residual ferromagnetic phases.

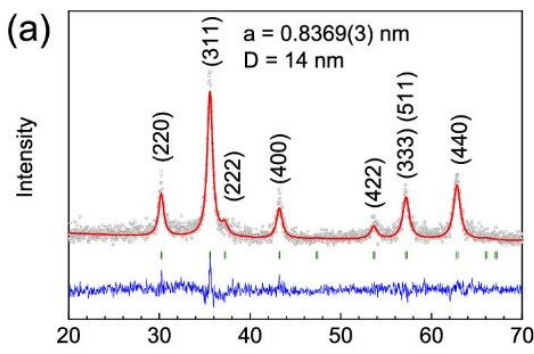

(b)

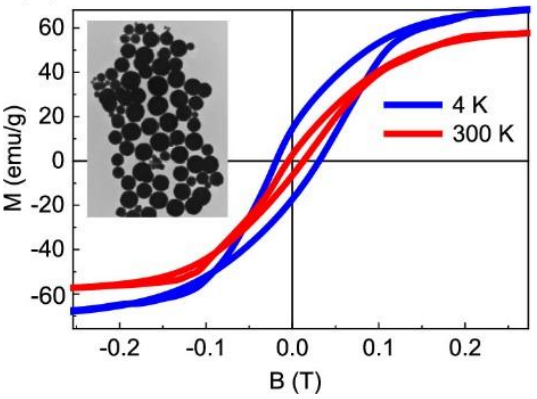

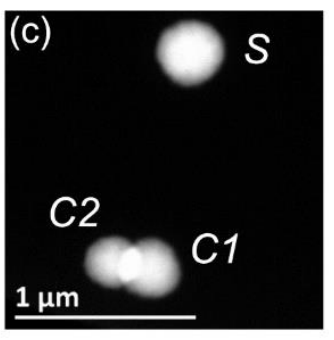

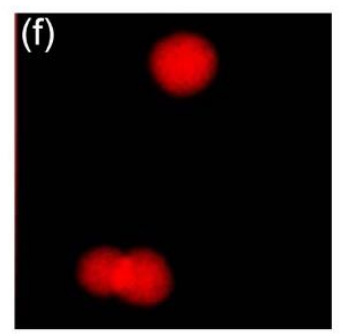

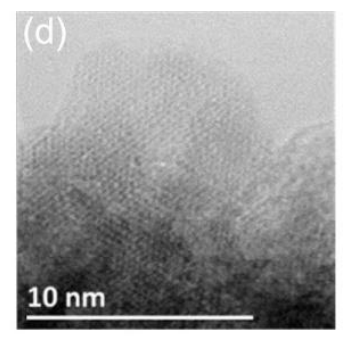
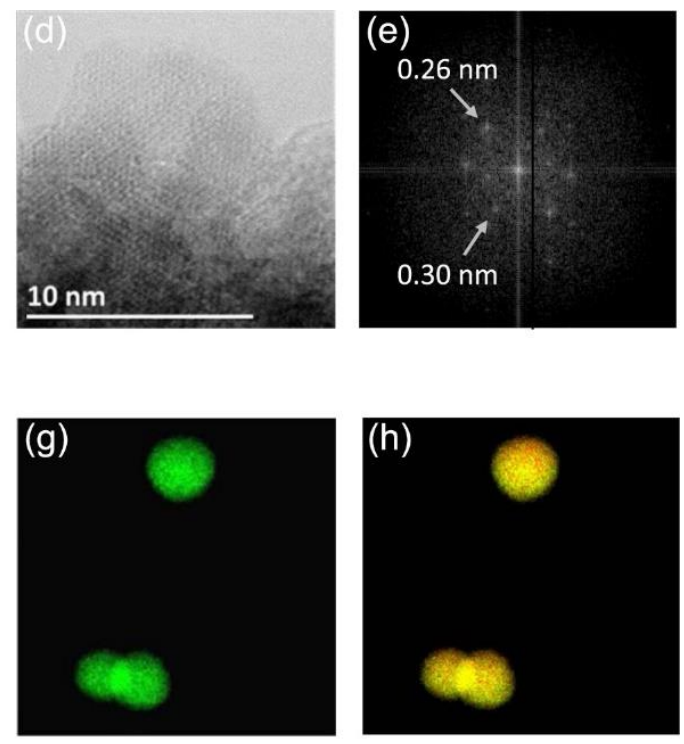

Figure 1. (a) X-ray diffraction (XRD) diffraction pattern of a powder of $\mathrm{Fe}_{3} \mathrm{O}_{4}$ particle-based clusters. (b) Magnetization curves of the powder at 4 and $300 \mathrm{~K}$. Inset is a transmission electron microscopy (TEM) image ( 3 $\times 5 \mathrm{~m}^{2}$ ) of a cluster assembly on a carbon substrate. (c) TEM image of three clusters studied by magnetic force microscopy (MFM), labeled S, C1, and C2. (d) TEM image of a border crystallite with the corresponding fast Fourier transform pattern (e) showing the presence of well-defined crystallographic structure. $(f, g)$ Chemical maps obtained by EDX spectroscopy of iron and oxygen distribution within the $\mathrm{Fe}_{3} \mathrm{O}_{4}$ cluster, respectively. (h) Relative chemical map with the distributions of both iron and oxygen within the clusters.

For accurate magnetic state measurements by MFM, it is essential to first evaluate the electrostatic interactions between the microscope probe and the sample. Indeed, the phase signal measured by MFM may contain a significant contribution from non-magnetic electrostatic forces, which arise from topographic effects and from inhomogeneous surface potentials between the clusters and substrate surface. (70-73) Therefore, we began our study by precisely evaluating the electrostatic contributions to the phase signal acquired in MFM. Our approach is to monitor the phase shift of the cantilever oscillation at specific tip-sample distances as a function of a bias voltage applied between the tip of the microscope and the sample substrate (igure 2a).

In the absence of electrostatic interactions, the phase signal as a function of the applied tip bias is expected to have a quadratic shape (parabola) centered at $0 \mathrm{~V}$. As shown in Figure $2 \mathrm{a}$ (also see Figure $\underline{\mathrm{S} 2}$ ), the parabolas are not symmetric with respect to $0 \mathrm{~V}$, as their maxima are shifted to about $+1 \mathrm{~V}$. This suggests the presence of an important intrinsic electrostatic contribution to the phase signal. It is also seen that, although the parabolas progressively flatten with tip-sample distance, they persist to at least $900 \mathrm{~nm}$. The parabolas recorded in the presence of an external out-of-plane magnetic field ranging from 15 to $55 \mathrm{mT}$ are shown in Figures $2 \mathrm{~b}$ and $\underline{\mathrm{S2}}$. As seen, the parabolas do not change with respect to the magnetic field, which confirms the possibility of compensating the electrostatic interactions by applying a bias voltage of $+1 \mathrm{~V}$ to the tip. Insights into the magnetic state of the clusters were gained by recording FD MFM images. Two sets of MFM images have been recorded: one without electrostatic compensation ( $0 \mathrm{~V}$, presented in Figure $\mathrm{S3})$ and another with an electrostatic compensation $(+1 \mathrm{~V})$, as shown in Figures 3 and $\underline{\mathrm{S}}$. 
(a)

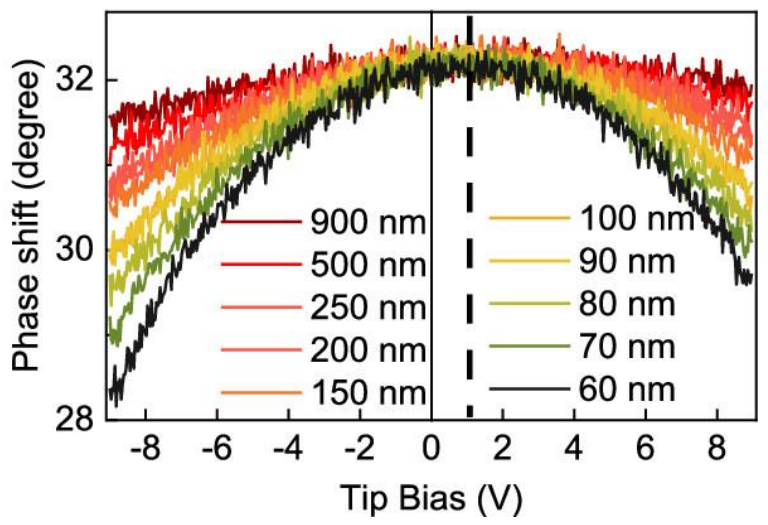

(b)

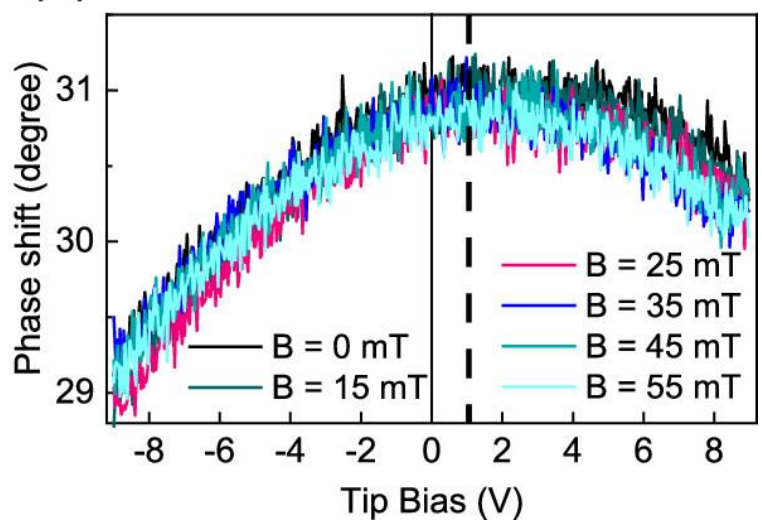

Figure 2. (a) Phase signal acquired above the cluster $S$ from Figure $1 \mathrm{c}$ as a function of tip bias for different tip lifts. (b) Phase signal taken above the cluster C2 as a function of tip bias and external magnetic field (lift $200 \mathrm{~nm}$ ). The dashed lines indicate the center of the parabolas located in each case at about $+1 \mathrm{~V}$ tip bias.

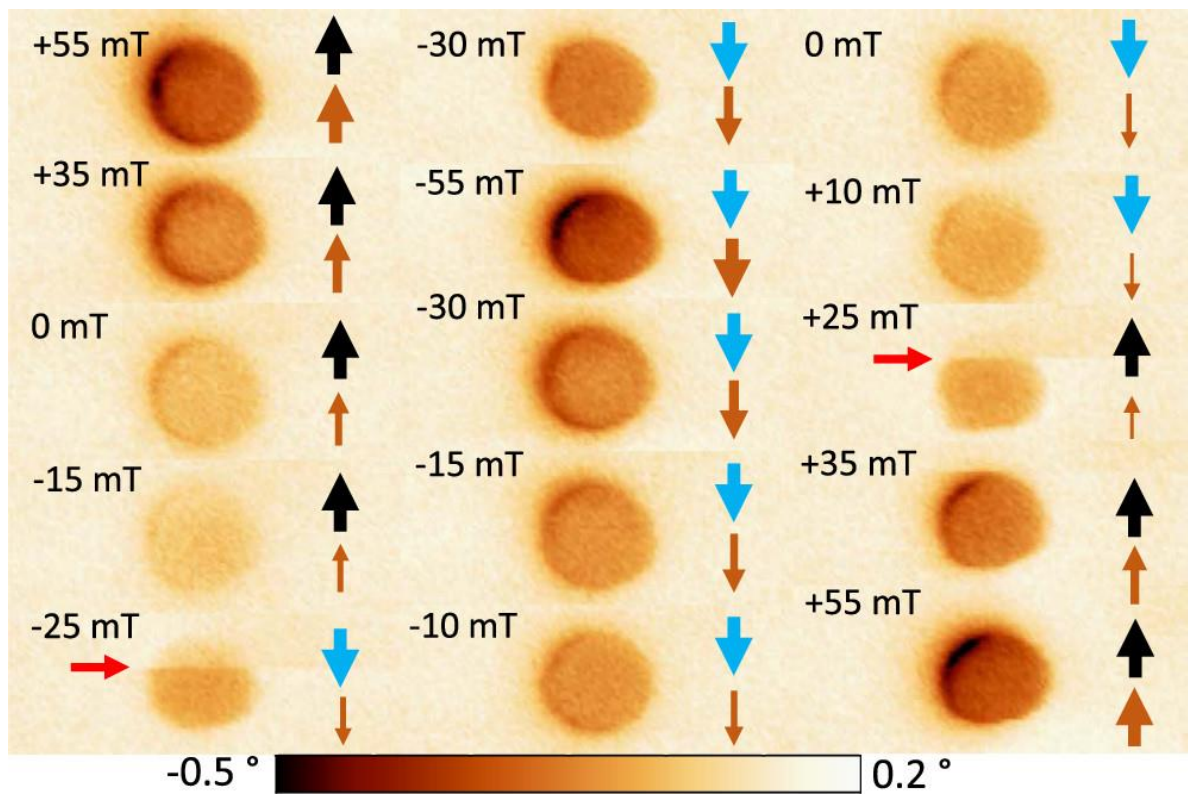

Figure 3. MFM images acquired on the isolated cluster from Figure $1 \mathrm{c}$ at different values of external magnetic field ranging between +55 and $-55 \mathrm{mT}$ (tip lift $=200 \mathrm{~nm}$ and $+1 \mathrm{~V}$ tip bias). Black and blue arrows represent the magnetization of the tip, while the brown arrows denote the cluster magnetization. The red arrows indicate the reversal of the tip magnetization.

Figure 3 shows FD-MFM images of the isolated cluster labeled $S$ in Figure $1 \mathrm{c}$, taken at $+1 \mathrm{~V}$ (full series of images in Figure S3). Starting at a magnetic field of $+55 \mathrm{mT}$, a dark (negative) contrast is observed over the cluster, which corresponds to an attractive interaction due to the parallel alignment of tip and cluster magnetization.

Decreasing the external magnetic field toward zero results in a decrease of the phase contrast. This indicates a decrease of the cluster magnetization along the $z$-axis (normal to the substrate plane), since the tip magnetization is constant in the respective magnetic field range (see below). A more complex situation is present in the field interval between $0 \mathrm{mT}$ and the coercive field of the tip at $-25 \mathrm{mT}$. In this interval, one could expect that the cluster magnetization aligns with the external field, that is, in the opposite direction with respect to the tip magnetization. The absence of bright contrast over the 
cluster nevertheless shows that this is not the case. In turn, the dark contrast reveals an attractive interaction, indicating that the magnetization components of the cluster and the tip are still oriented in the same direction (as depicted by arrows in Figure 3). This shows that the magnetization of the cluster is influenced by the stray field of the magnetic tip that overcomes the external magnetic field in this interval. In fact, variations of the sample magnetization induced by MFM magnetic tips have been observed in MFM experiments, (74-78) while the axial stray field of the tips have indeed been found in the $\mathrm{mT}$ range. $(79,80)$

Based on the above observations, the magnetization of the cluster is schematized in Figure 3 by arrows (brown) of various thicknesses, while the magnetization of the tip is represented by black and blue arrows. It can thus be deduced that at $0 \mathrm{mT}$, the dark MFM contrast (attractive interaction) is caused by the tip magnetic stray-field that induces a residual magnetization in the cluster. At $-25 \mathrm{mT}$ (red arrow in Figure 3 ), the tip coercive field is reached, and the tip magnetization suddenly reverses. The stray field of the tip points then along the same direction as the external field, explaining the larger MFM signal below the position indicated by the red arrow. It is then followed by a progressive increase of the dark contrast as the external magnetic field is swept toward more negative values.

The contrast dynamics over the cluster follows the same trend when sweeping back the external magnetic field from -55 to $+55 \mathrm{mT}$. The tip coercive field is reached at $+25 \mathrm{mT}$ (red arrow in Figure 3 ). Along the entire magnetic cycle, a dominant dark contrast is therefore observed in FD-MFM images corresponding to a single magnetic domain configuration. This is consistent with a coherent rotation of the spins of multiple parts forming the cluster, indicating that the cluster behaves as a macro-spin. In addition, the observed uniform dark contrast induced by tip stray-field, that is, in the absence of an external magnetic field reflects a low value of the overall anisotropy energy of the cluster.

By a one-by-one analysis of the FD-MFM images, an average phase signal over the cluster can be obtained. Figure $4 a, b$ shows the variation of the average phase signal as a function of the external magnetic field, for a tip bias of 0 and $+1 \mathrm{~V}$, respectively. A butterfly-like loop is observed in both cases. $A t+1 \mathrm{~V}$, the compensation of electrostatic effects induces a downward shift of the butterfly loop, providing a clearer magnetic signal of the sample. It might be expected that the magnetic field of the tip adds to the external field, resulting in a shift of the magnetic field axis and in a deformation of the MFM hysteresis curves. However, the magnetization of the clusters follows the magnetization direction of the tip (interaction always attractive). This means that the resulting MFM hysteresis loop reflects the tip magnetization behavior rather than of the cluster. As a consequence, in the limit of our field resolution, a shift of the MFM hysteresis loop is not observed.

The electrostatic contribution interferes with the "magnetic" phase signal. As seen in Figure 4a in the interval -10 and $-25 \mathrm{mT}$, the values of the magnetic phase shift are positive, which in principle must denote a repulsive interaction experienced by the tip. This is a clear visualization of the effect of the electrostatic field. Without the electrostatic interaction as shown in Figure $4 \mathrm{~b}$, the butterfly loop is fully located at negative values as the tip stray-field and the external magnetic field maintains an attractive magnetic interaction. The second effect induced by electrostatic interactions and observed in Figure $\underline{4} \mathrm{a}$ is the asymmetry of the butterfly loop, when the external field is reversed. Indeed, when the electrostatic contribution is compensated [Figure 4b], the butterfly loop is far more symmetric, also being less distorted. These effects brought by the electrostatic fields can be seen even better when looking at the hysteresis loops obtained after considering the sharp reversal of the tip magnetization at $\pm 25 \mathrm{mT}$ [Figure $4 \mathrm{c}, \mathrm{d}$ ] . 
(a)

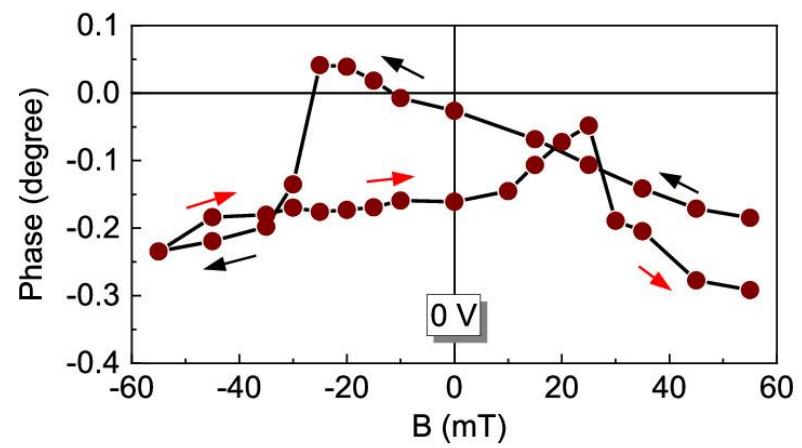

(c)

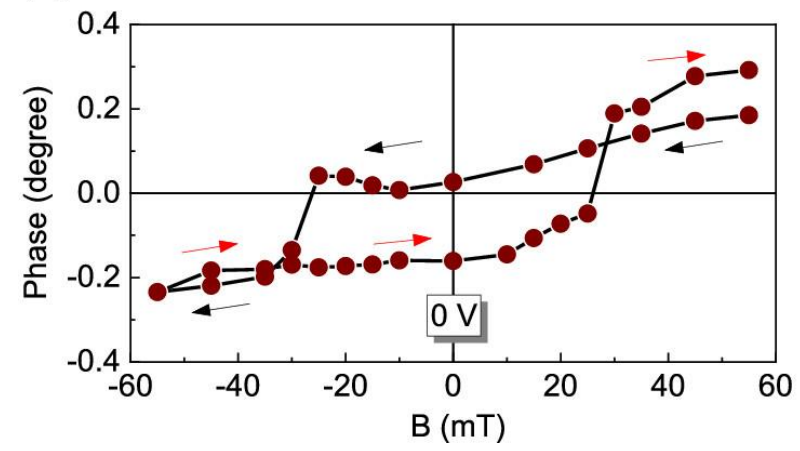

(b)

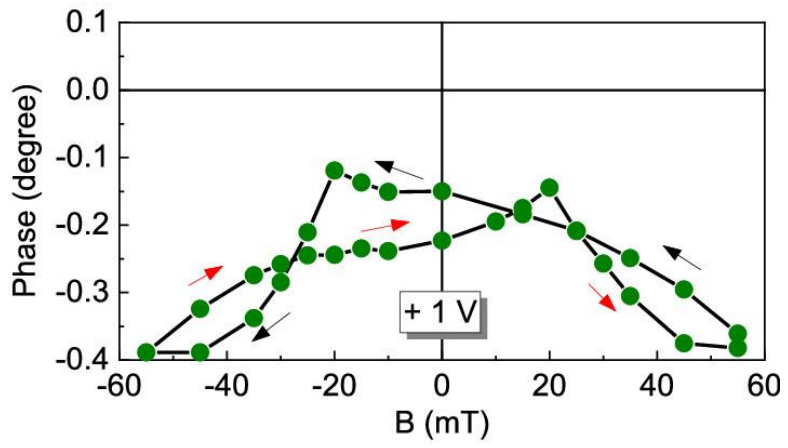

(d)

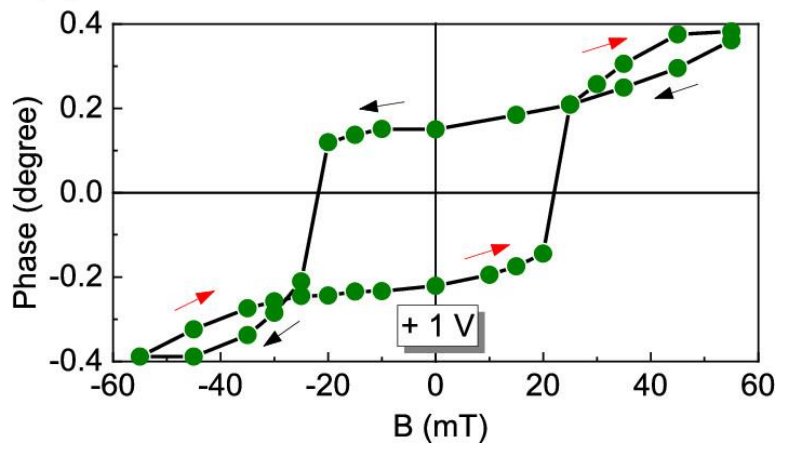

Figure 4. $(a, b)$ FD-MFM average phase signals at 0 and $+1 \mathrm{~V}$, respectively, acquired over the isolated cluster from Figure 1c. Tip lift: $200 \mathrm{~nm}$. (c,d) Corresponding hysteresis loops obtained by considering the tip magnetization reversal. Arrows indicate back and forth sweeping of the external magnetic field.

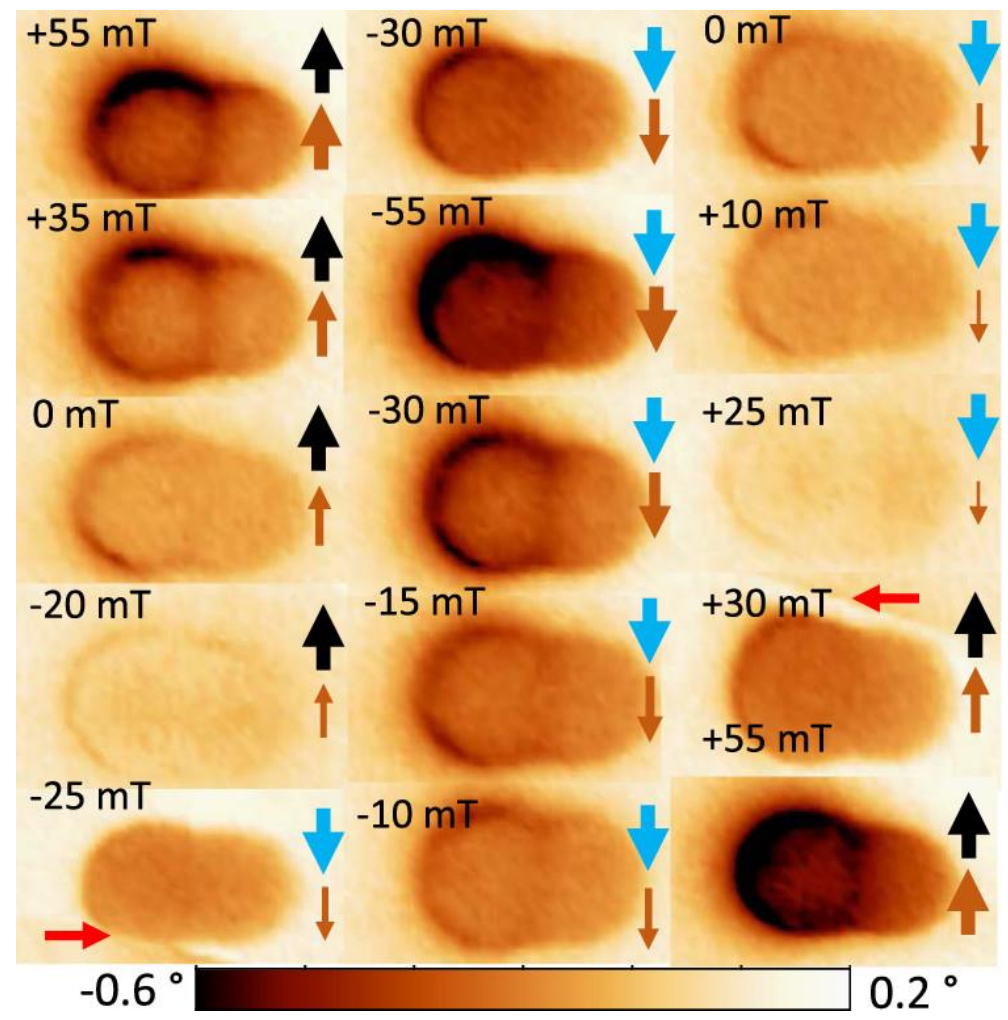

Figure 5. FD-MFM images acquired on the two adjacent clusters from Figure $1 \mathrm{c}$ at different values of external magnetic field ranging between +55 and $-55 \mathrm{mT}$ (tip lift $=200 \mathrm{~nm}$ and $+1 \mathrm{~V}$ tip bias). Black and blue arrows represent the magnetization of the tip, while the brown arrows denote the cluster magnetization The red arrows indicate the reversal of the tip magnetization. 
The resulting hysteresis loop from Figure $4 \mathrm{~d}$ has a shape given mainly by the magnetization reversal of the microscope tip. Before further strengthening this conclusion by presenting results on highly anisotropic CoPt nanoislands (coercive fields $>300 \mathrm{mT}$ and close to $100 \%$ of remnant magnetization), we hereafter present the findings on the two clusters seen in the lower part of Figure 1c. As above, the FD-MFM images were recorded with and without electrostatic contributions. FD-MFM images taken at $+1 \mathrm{~V}$ are shown in Figure 5 , full series of images at $+1 \mathrm{~V}$ and $0 \mathrm{~V}$ can be seen in Figures $\mathrm{S} 6$ and $\underline{\mathrm{SI}}$, respectively. The dark contrast in Figure 5 shows a similar trend as before for the isolated cluster. The tip magnetization reversal for both, back and forth magnetic sweeping directions, takes place at -25 and $+30 \mathrm{mT}$, respectively. The dark contrast is uniform over both clusters along the entire magnetic cycle, which speaks in favor of a SP behavior of both clusters as in the case of the isolated cluster.

Phase butterfly-like loops are observed for both clusters [labeled C1 (largest) and C2 (smallest), Figure $\underline{6} a, b]$. No positive value of the magnetic phase shift is detected over the entire cycle, suggesting weaker electrostatic effects [Figure 6a]. Indeed, they are expected to be reduced by the proximity of the two clusters, which decreases the topographic variations. (70) Consequently, the downward shifts of the butterfly-like loops [Figure $6 a, b]$ and of the resulting hysteresis loops [Figure $6 c, d$ ] are not so pronounced when compensating the electrostatic contribution, as compared to the isolated cluster. The fact that the phase signal delivered by the two clusters is higher with respect to the isolated cluster can also play a role. Above adjacent clusters, the tip collects a higher magnetic signal, the phase values being greater as compared to an isolated cluster. This observation strengthens the above conclusions that the hysteresis loops reflect the magnetic reversal of the tip.

(a)

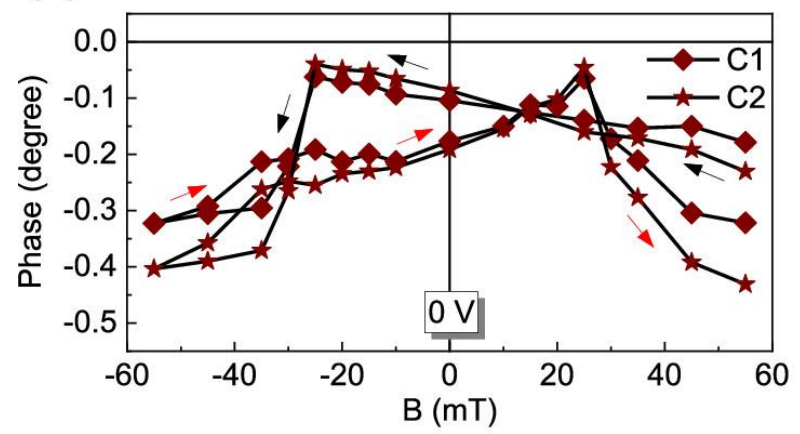

(c)

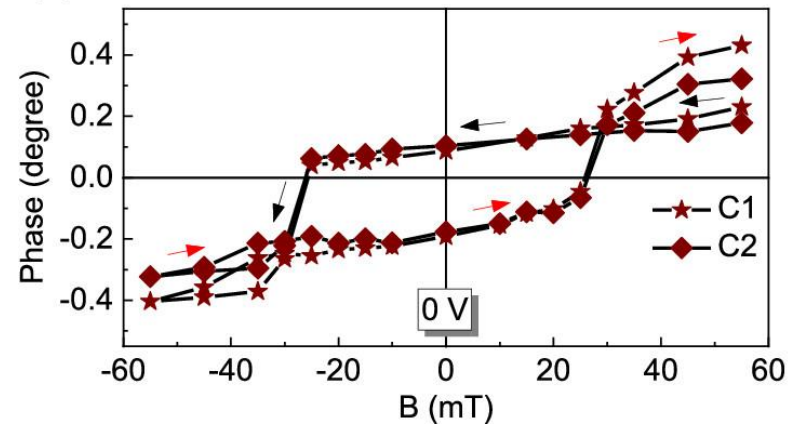

(b)

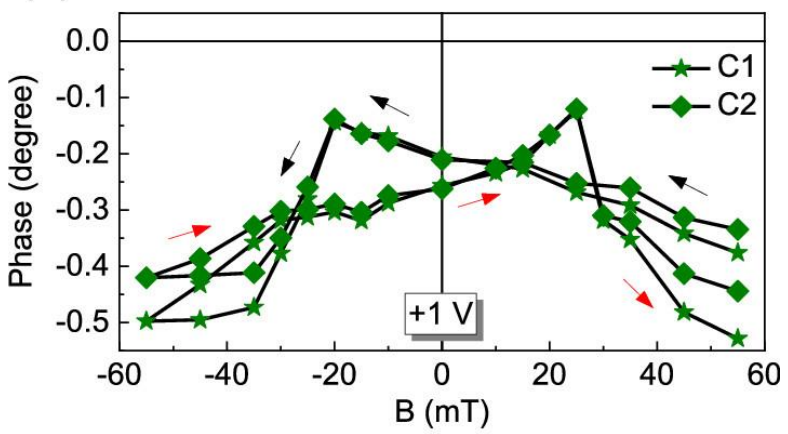

(d)

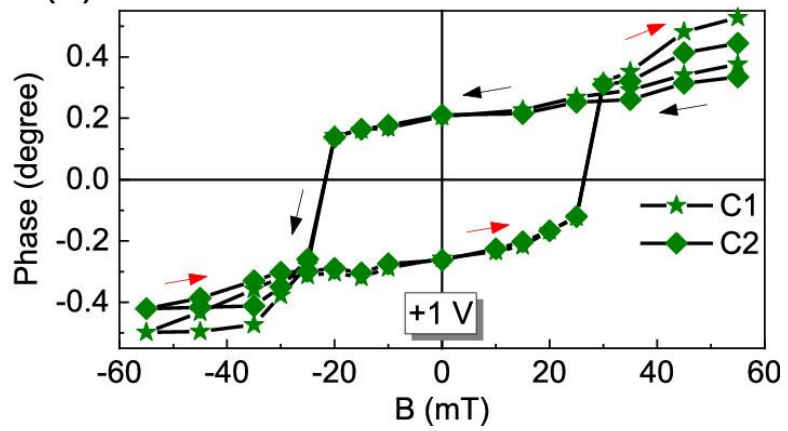

Figure 6. (a,b) FD-MFM average phase signals at 0 and $+1 \mathrm{~V}$ acquired on $\mathrm{C} 1$ [right-hand cluster in the "dimer" from Figure 1c] and on C2 [left-hand cluster in the "dimer" from Figure 1c], as a function of the external magnetic field. Tip lift: $200 \mathrm{~nm}$. (c,d) Corresponding hysteresis loops considering the tip magnetization reversal. Arrows indicate the back and forth sweeping of the external magnetic field.

To support these findings, we conducted experiments on hard magnetic samples consisting on CoPt islands of $45 \mathrm{~nm}$ in height and $200 \mathrm{~nm}$ in diameter [Figure 7a]. Due to the strong spin-orbit coupling, 
these islands have a large out-of-plane anisotropy, and a large coercive field in the range 350-550 mT, which is more than ten times larger than the tip coercive field. (81) As a consequence, the magnetization of the CoPt islands is blocked at room temperature and constant in the field interval explored in the present MFM study. (81) Changes in phase contrast with the external magnetic field can then be exclusively ascribed to the variation/reversal of the tip magnetization. With a zero external magnetic field, the magnetic contrast is either dark (negative) or bright (positive) [Figure 7b], denoting a parallel or antiparallel orientation of the magnetization, respectively. The quartz substrate supporting the CoPt islands has a different dielectric constant as compared to the carbon TEM grid and a far larger thickness of about $1 \mathrm{~mm}$. For this reason, the maxima of the parabolas are shifted to approximately-5.0 V, which is significant [Figure 7c]. The electrostatic contribution to the magnetic signal is therefore expected high.

(a)
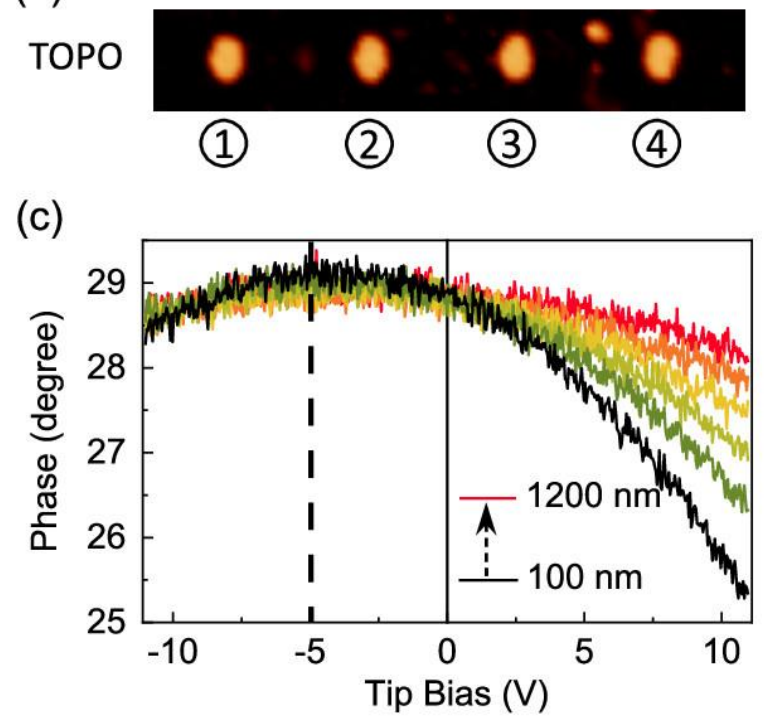

(b)

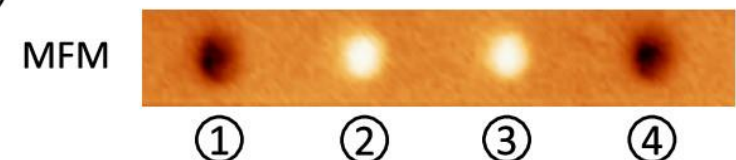

(d)

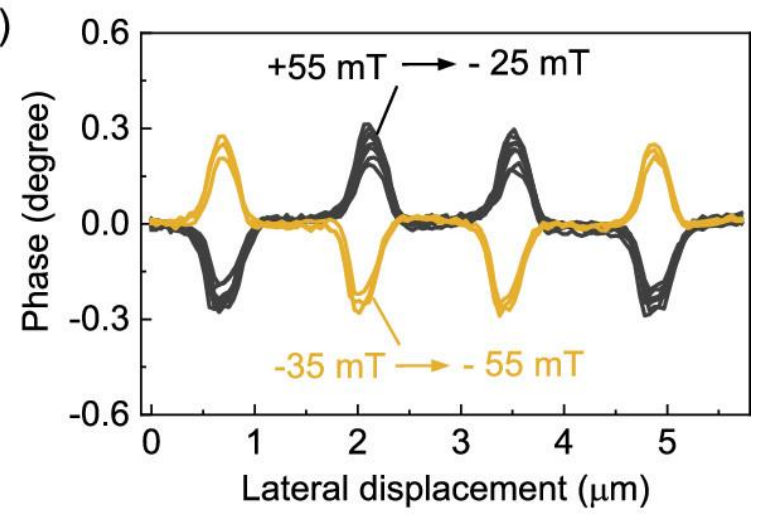

(e)

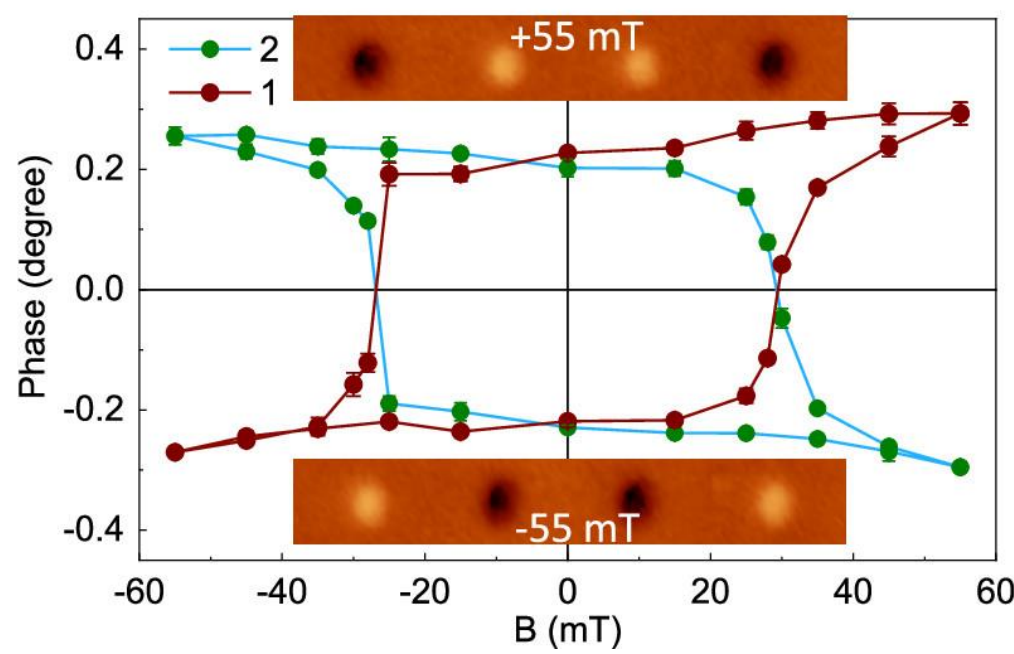

Figure 7. (a) Topographic AFM image $\left(6 \times 1 \mu \mathrm{m}^{2}\right)$ and its corresponding MFM phase image (b) taken at $200 \mathrm{~nm}$ lift and a tip bias of $-5.0 \mathrm{~V}$. The numbers label the CoPt islands. (c) Phase signal as a function of applied tip bias, recorded at lifts ranging from 100 to $1200 \mathrm{~nm}$. The black dashed lines indicate that the center of the parabolas are located at $-5.0 \mathrm{~V}$ tip bias. (d) Phase profiles along the four CoPt islands displayed in (a) as a function of external magnetic field (lift of $200 \mathrm{~nm}$ and tip bias of $-5.0 \mathrm{~V}$ ). (e) MFM hysteresis loops obtained by measuring the CoPt islands (island 1 and island 2) at a lift of $200 \mathrm{~nm}$ and a tip bias of $-5.0 \mathrm{~V}$. Insets show the phase images of the islands recorded at $+55 \mathrm{mT}$ and $-55 \mathrm{mT}$, highlighting the magnetic contrast inversion owing to tip magnetization reversal. 
An MFM image of four CoPt islands acquired with $-5.0 \mathrm{~V}$ applied to the tip is shown in Figure $7 \mathrm{~b}$. At the maximum applied magnetic field of $+55 \mathrm{mT}$, a dark contrast is observed over the island 1 and 4 , while islands 2 and 3 exhibit a bright (positive) contrast [Figure 7d]. The phase signal recorded over all islands reverses when reaching a magnetic field of $-28 \mathrm{mT}$ [Figure 7d]. Sweeping backward the external magnetic field, the initial phase signal is recovered when applying $+30 \mathrm{mT}$ (Figure S7).

The average phase signal as a function of the external magnetic field for both types of magnetized islands therefore results in typical hysteresis loops of the tip (Figure 7e). This is because the CoPt magnetization is strictly constant in this field interval. In addition, the sudden switch of the signal over CoPt islands reveals that the reversal of tip magnetization occurs in a reduced field range, suggesting a strong bimodal state of the tip magnetization, that is, up and down. These conclusions, along with the fact that the phase contrast reverses above the clusters at the same fields $(-28$ and $+30 \mathrm{mT})$ again demonstrate that the hysteresis loops acquired on the clusters can be directly associated to the tip magnetization behavior.

\section{Reconstruction of Magnetization Behavior of the Clusters}

To retrace the FD magnetization behavior of the clusters, one possibility is to subtract the magnetization switching of the tip. The simplest way is to consider a square hysteresis loop for the tip. Similar to the case of diamagnetic corrections realized for weak magnetic samples, it is first required to establish a correction factor. The slope of the phase signal before the coercive fields (either flip direction) is rather constant [see black or red arrows in Figures $4 \mathrm{~d}$ and $\underline{6} \mathrm{~d}$ ]. Under these conditions, a correction factor can be the phase signal at zero magnetic field, which is slightly different for different clusters and sweeping directions.

(a)

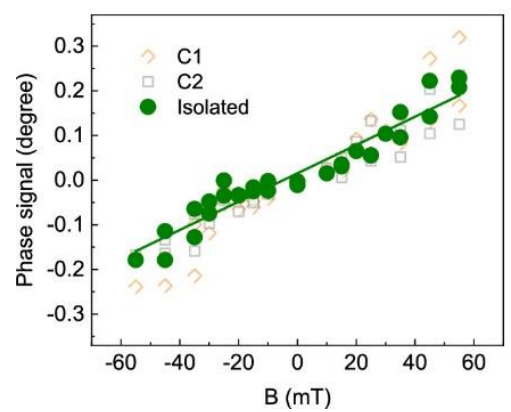

(b)

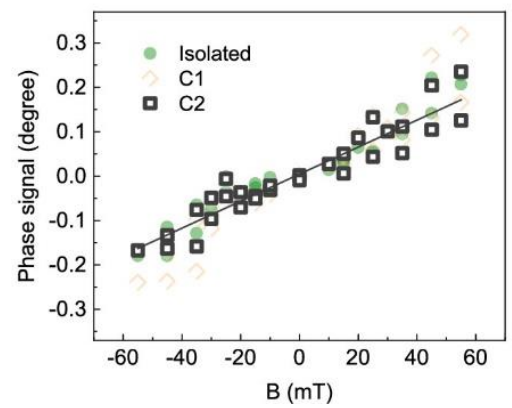

(c)

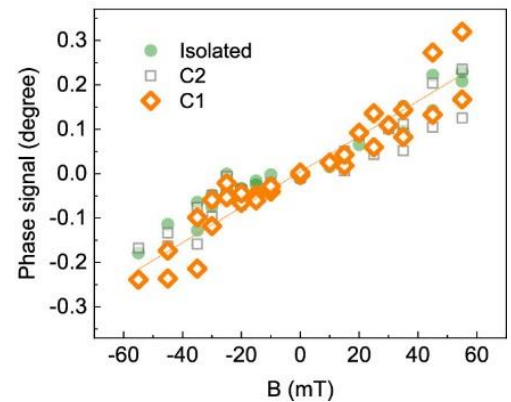

Figure 8. FD phase signal for the three clusters from Figure 1c, obtained by considering the magnetic reversal of the microscope tip. Data highlighted in (a) is for the isolated $S$ cluster, in (b) is for C2 cluster, and in (c) is for C1 cluster. Solid lines are linear fits. Error bars are below $15 \%$ of the phase signal (not included for clarity).

Figure 8 shows the phase signal of the three investigated clusters, obtained by subtracting, for each cluster, the phase shift measured at zero field. The data for all clusters drop on rather imperfect linear variations [Figure 8a isolated $S$ cluster, (b) $\mathrm{C} 2$, and (c) $\mathrm{C} 1$ ]. Nonetheless, the curves from Figure 8 show a progressive increase of the cluster magnetization with the magnetic field, and the absence of a hysteresis, indicating a SP behavior of these individual clusters supported by a substrate. Our magnetic field $(<55 \mathrm{mT})$, as well as the impossibility to perform low-temperature experiments with our microscope does not allow us to further support this conclusion. The SP behavior revealed in the present MFM study is in agreement with the small dimension of crystallites (14 $\mathrm{nm}$ ) composing the clusters, as the critical size of magnetite to enter ferromagnetic regime at room temperature is about $30 \mathrm{~nm}$. In dried powders, as generally measured by VSM or SQUID magnetometry, the clusters are 
most likely assembled in large aggregates which, upon a first exposure to an external magnetic field, are prone to develop magnetic dipolar interactions and finally ferromagnetic characteristics, as observed in our VSM curves. Dipolar interactions in highly concentrated suspensions of $13 \mathrm{~nm}$ maghemite NPs were in fact observed by temperature-dependent magnetization measurements. (82) However, to date, a clear picture on inter-particle interactions mediated by ligands is not yet available. In this regard, our approach based on FD-MFM investigation of individual clusters can be extended to other systems such as nanoflowers or hollow spheres. $(45,48)$

\section{Conclusions}

In conclusion, large iron-oxide nanoparticulate clusters have been synthesized in a quick (1 h) and one step process. According to TEM-EDX and XRD analysis, the clusters display a poly-crystalline multicore structure and an overall spherical shape with sizes of the order of few hundreds of nanometers. The magnetization state of individual clusters has been probed at room temperature by FD magnetic force microcopy. It was found that after an in situ removing of electrostatic interactions, which are known to affect the phase signals in magnetic force microscopy, it is possible to retrace the FD magnetization behavior of individual clusters in interaction with the microscope tip. The resulting magnetization loops display a typical butterfly-like shape resulting mainly from the magnetization reversal of the tip, as separately demonstrated on hard magnetic CoPt islands. After taking into account the magnetization reversals of the tip, the MFM phase signals reveal a gradual increase of the magnetization of the clusters with the magnetic field, and the absence of a hysteresis in the limit of magnetic fields below $55 \mathrm{mT}$, suggesting a SP behavior. Overall, these results show an effective experimental procedure for probing large magnetic clusters with variable sizes and shapes, as needed for many biomedical applications. Our approach can readily be used for temperature-dependent experiments or to confirm the SP character of clusters composed of crystallites of various sizes.

\section{Supporting Information}

The Supporting Information is available free of charge at https://pubs-acs-org.scd-rproxy.ustrasbg.fr/doi/10.1021/acs.jpcc.1c05426. Magnetic characterization of the clusters (in powder) as a function of magnetic field and temperature and complete series of field-dependent MFM images, as well as a characterization of the magnetic-field in the AFM microscope (PDF)

\section{Author Information}

\section{Corresponding Author:}

M. V. Rastei - Institut de Physique et Chimie des Matériaux de Strasbourg, UMR 7504 CNRS, Université de Strasbourg, Strasbourg F-67034, France; https://orcid.org/0000-0003-39271409; Email: rastei@ipcms.unistra.fr

\section{Authors:}


C. lacovita - Institut de Physique et Chimie des Matériaux de Strasbourg, UMR 7504 CNRS, Université de Strasbourg, Strasbourg F-67034, France; Department of Pharmaceutical Physics-Biophysics, Faculty of Pharmacy, Iuliu Hatieganu University of Medicine and Pharmacy, Cluj-Napoca 400349, Romania

R. Dudric - Faculty of Physics, "Babes-Bolyai" University, Cluj-Napoca 400084, Romania

M. Vomir - Institut de Physique et Chimie des Matériaux de Strasbourg, UMR 7504 CNRS, Université de Strasbourg, Strasbourg F-67034, France

O. Ersen - Institut de Physique et Chimie des Matériaux de Strasbourg, UMR 7504 CNRS, Université de Strasbourg, Strasbourg F-67034, France; https://orcid.org/0000-0002-1553-0915

B. Donnio - Institut de Physique et Chimie des Matériaux de Strasbourg, UMR 7504 CNRS, Université de Strasbourg, Strasbourg F-67034, France; https://orcid.org/0000-0001-5907-7705

J. L. Gallani - Institut de Physique et Chimie des Matériaux de Strasbourg, UMR 7504 CNRS, Université de Strasbourg, Strasbourg F-67034, France

\section{Notes}

The authors declare no competing financial interest.

\section{Acknowledgement}

This work is supported by ANR OH-RISQUE SMARAGD (14 OHRI 0008 01), ANR-11-LABX-0058-NIE within the Investissement d'Avenir program ANR-10-IDEX-0002-02, and Romanian Ministry of Education and Research, CNCS-UEFISCDI, project number PN-III-P2-2.1-PED-2019-3283, within PNCDI III.

\section{References}

This article references 82 other publications.

1. Xiao, Y.; Du, J. Superparamagnetic nanoparticles for biomedical applications. J. Mater. Chem. B 2020, 8, 354- 367, DOI: 10.1039/c9tb01955c [Crossref], [PubMed], [CAS], Google Scholar

2. Colombo, M.; Carregal-Romero, S.; Casula, M. F.; Gutiérrez, L.; Morales, M. P.; Böhm, I. B.; Heverhagen, J. T.; Prosperi, D.; Parak, W. J. Biological applications of magnetic nanoparticles. Chem. Soc. Rev. 2012, 41, 4306- 4334, DOI: 10.1039/c2cs15337h [Crossref], [PubMed], [CAS], Google Scholar

3. Dulińska-Litewka, J.; Łazarczyk, A.; Hałubiec, P.; Szafrański, O.; Karnas, K.; Karewicz, A. Superparamagnetic Iron Oxide Nanoparticles-Current and Prospective Medical Applications. Materials 2019, 12, 617, DOI: 10.3390/ma12040617 [Crossref], [CAS], Google Scholar

4. Abarca-Cabrera, L.; Fraga-García, P.; Berensmeier, S. Bio-nano interactions: binding proteins, polysaccharides, lipids and nucleic acids onto magnetic nanoparticles. Biomater. Res. 2021, 25, 12, DOI: 10.1186/s40824-021-00212-y [Crossref], [PubMed], [CAS], Google Scholar 
5. Zhang, L.; Qiao, S.; Jin, Y.; Yang, H.; Budihartono, S.; Stahr, F.; Yan, Z.; Wang, X.; Hao, Z.; Lu, G. Q. Fabrication and Size-Selective Bioseparation of Magnetic Silica Nanospheres with Highly Ordered Periodic Mesostructure. Adv. Funct. Mater. 2008, 18, 3203-3212, DOI: 10.1002/adfm.200800363 [Crossref], [CAS], Google Scholar

6. Mahmoudi, M.; Simchi, A.; Imani, M.; Häfeli, U. O. Superparamagnetic Iron Oxide Nanoparticles with Rigid Cross-linked Polyethylene Glycol Fumarate Coating for Application in Imaging and Drug Delivery. J. Phys. Chem. C 2009, 113, 8124- 8131, DOI: 10.1021/jp900798r [ACS Full Text ], [CAS], Google Scholar

7. Shkilnyy, A.; Munnier, E.; Hervé, K.; Soucé, M.; Benoit, R.; Cohen-Jonathan, S.; Limelette, P.; Saboungi, M.-L.; Dubois, P.; Chourpa, I. Synthesis and Evaluation of Novel Biocompatible Super-paramagnetic Iron Oxide Nanoparticles as Magnetic Anticancer Drug Carrier and Fluorescence Active Label. J. Phys. Chem. C 2010, 114, 5850- 5858, DOI: 10.1021/jp9112188 [ACS Full Text ], [CAS], Google Scholar

8. Suciu, M.; Ionescu, C. M.; Ciorita, A.; Tripon, S. C.; Nica, D.; Al-Salami, H.; Barbu-Tudoran, L. Applications of superparamagnetic iron oxide nanoparticles in drug and therapeutic delivery, and biotechnological advancements. Beilstein J. Nanotechnol. 2020, 11, 1092-1109, DOI: 10.3762/bjnano.11.94 [Crossref], [PubMed], [CAS], Google Scholar

9. Lee, J.-H.; Kim, B.; Kim, Y.; Kim, S.-K. Ultra-high rate of temperature increment from superparamagnetic nanoparticles for highly efficient hyperthermia. Sci. Rep. 2021, 11, 4969, DOI: 10.1038/s41598-021-84424-1 [Crossref], [PubMed], [CAS], Google Scholar

10. Etemadi, H.; Plieger, P. G. Magnetic Fluid Hyperthermia Based on Magnetic Nanoparticles: Physical Characteristics, Historical Perspective, Clinical Trials, Technological Challenges, and Recent Advances. Adv. Ther. 2020, 3, 2000061, DOI: 10.1002/adtp.202000061 [Crossref], Google Scholar

11. Blanco-Andujar, C.; Walter, A.; Cotin, G.; Bordeianu, C.; Mertz, D.; Felder-Flesch, D.; BeginColin, S. Design of iron oxide-based nanoparticles for MRI and magnetic hyperthermia. Nanomedicine 2016, 11, 1889-1910, PMID: 27389703 DOI: 10.2217/nnm-2016-5001 [Crossref], [PubMed], [CAS], Google Scholar

12. Sun, C.; Du, K.; Fang, C.; Bhattarai, N.; Veiseh, O.; Kievit, F.; Stephen, Z.; Lee, D.; Ellenbogen, R. G.; Ratner, B.; Zhang, M. PEG-Mediated Synthesis of Highly Dispersive Multifunctional Superparamagnetic Nanoparticles: Their Physicochemical Properties and Function In Vivo. ACS Nano 2010, 4, 2402-2410, PMID: 20232826 DOI: 10.1021/nn100190v [ACS Full Text], [CAS], Google Scholar

13. Hu, F.; MacRenaris, K. W.; Waters, E. A.; Liang, T.; Schultz-Sikma, E. A.; Eckermann, A. L.; Meade, T. J. Ultrasmall, Water-Soluble Magnetite Nanoparticles with High Relaxivity for Magnetic Resonance Imaging. J. Phys. Chem. C 2009, 113, 20855- 20860, PMID: 24991303 DOI: 10.1021/jp907216g [ACS Full Text], [CAS], Google Scholar

14. Lin, Y.; Zhang, K.; Zhang, R.; She, Z.; Tan, R.; Fan, Y.; Li, X. Magnetic nanoparticles applied in targeted therapy and magnetic resonance imaging: crucial preparation parameters, indispensable pre-treatments, updated research advancements and future perspectives. $J$. Mater. Chem. B 2020, 8, 5973- 5991, DOI: 10.1039/d0tb00552e [Crossref], [PubMed], [CAS], Google Scholar

15. Wu, K.; Su, D.; Saha, R.; Liu, J.; Chugh, V. K.; Wang, J.-P. Magnetic Particle Spectroscopy: A Short Review of Applications Using Magnetic Nanoparticles. ACS Appl. Nano Mater. 2020, 3, 4972- 4989, DOI: 10.1021/acsanm.0c00890 [ACS Full Text], [CAS], Google Scholar

16. Fortin, J.-P.; Wilhelm, C.; Servais, J.; Ménager, C.; Bacri, J.-C.; Gazeau, F. Size-Sorted Anionic Iron Oxide Nanomagnets as Colloidal Mediators for Magnetic Hyperthermia. J. Am. Chem. Soc. 2007, 129, 2628- 2635, PMID: 17266310 DOI: 10.1021/ja067457e [ACS Full Text], [CAS], Google Scholar

17. Demortière, A.; Panissod, P.; Pichon, B. P.; Pourroy, G.; Guillon, D.; Donnio, B.; Bégin-Colin, S. Size-dependent properties of magnetic iron oxidenanocrystals. Nanoscale 2011, 3, 225232, DOI: 10.1039/c0nr00521e [Crossref], [PubMed], [CAS], Google Scholar 
18. Smart, J. S. The Néel Theory of Ferrimagnetism. Am. J. Phys. 1955, 23, 356-370, DOI: 10.1119/1.1934006 [Crossref], [CAS], Google Scholar

19. Levy, M.; Quarta, A.; Espinosa, A.; Figuerola, A.; Wilhelm, C.; García-Hernández, M.; Genovese, A.; Falqui, A.; Alloyeau, D.; Buonsanti, R.; Cozzoli, P. D.; García, M. A.; Gazeau, F.; Pellegrino, T. Correlating Magneto-Structural Properties to Hyperthermia Performance of Highly Monodisperse Iron Oxide Nanoparticles Prepared by a Seeded-Growth Route. Chem. Mater. 2011, 23, 4170-4180, DOI: 10.1021/cm201078f [ACS Full Text ], [CAS], Google Scholar

20. Tong, S.; Quinto, C. A.; Zhang, L.; Mohindra, P.; Bao, G. Size-Dependent Heating of Magnetic Iron Oxide Nanoparticles. ACS Nano 2017, 11, 6808-6816, PMID: 28625045 DOI: 10.1021/acsnano.7b01762 [ACS Full Text ], [CAS], Google Scholar

21. Huang, J. H.; Parab, H. J.; Liu, R.-S.; Lai, T.-C.; Hsiao, M.; Chen, C.-H.; Sheu, H.-S.; Chen, J.-M.; Tsai, D.-P.; Hwu, Y.-K. Investigation of the Growth Mechanism of Iron Oxide Nanoparticles via a Seed-Mediated Method and Its Cytotoxicity Studies. J. Phys. Chem. C 2008, 112, 1568415690, DOI: 10.1021/jp803452j [ACS Full Text ], [CAS], Google Scholar

22. Guardia, P.; Labarta, A.; Batlle, X. Tuning the Size, the Shape, and the Magnetic Properties of Iron Oxide Nanoparticles. J. Phys. Chem. C 2011, 115, 390- 396, DOI: 10.1021/jp1084982 [ACS Full Text ], [CAS], Google Scholar

23. Nemati, Z.; Alonso, J.; Rodrigo, I.; Das, R.; Garaio, E.; García, J. Á.; Orue, I.; Phan, M.-H.; Srikanth, H. Improving the Heating Efficiency of Iron Oxide Nanoparticles by Tuning Their Shape and Size. J. Phys. Chem. C 2018, 122, 2367-2381, DOI: 10.1021/acs.jpcc.7b10528 [ACS Full Text ], [CAS], Google Scholar

24. Cheah, P.; Cowan, T.; Zhang, R.; Fatemi-Ardekani, A.; Liu, Y.; Zheng, J.; Han, F.; Li, Y.; Cao, D.; Zhao, Y. Continuous growth phenomenon for direct synthesis of monodisperse water-soluble iron oxide nanoparticles with extraordinarily high relaxivity. Nanoscale 2020, 12, 92729283, DOI: 10.1039/d0nr01552k [Crossref], [PubMed], [CAS], Google Scholar

25. Ma, J.; Chen, K. Discovery of superparamagnetism in sub-millimeter-sized magnetite porous single crystals. Phys. Lett. A 2016, 380, 3313-3318, DOI: 10.1016/j.physleta.2016.07.065 [Crossref], [CAS], Google Scholar

26. Ganesan, V.; Lahiri, B. B.; Louis, C.; Philip, J.; Damodaran, S. P. Size-controlled synthesis of superparamagnetic magnetite nanoclusters for heat generation in an alternating magnetic field. J. Mol. Liq. 2019, 281, 315-323, DOI: 10.1016/j.molliq.2019.02.095 [Crossref], [CAS], Google Scholar

27. Bigall, N. C.; Wilhelm, C.; Beoutis, M.-L.; García-Hernandez, M.; Khan, A. A.; Giannini, C.; Sánchez-Ferrer, A.; Mezzenga, R.; Materia, M. E.; Garcia, M. A.; Gazeau, F.; Bittner, A. M.; Manna, L.; Pellegrino, T. Colloidal Ordered Assemblies in a Polymer Shell-A Novel Type of Magnetic Nanobeads for Theranostic Applications. Chem. Mater. 2013, 25, 1055- 1062, DOI: 10.1021/cm3036746 [ACS Full Text ], [CAS], Google Scholar

28. Dallet, L.; Stanicki, D.; Voisin, P.; Miraux, S.; Ribot, E. J. Micron-sized iron oxide particles for both MRI cell tracking and magnetic fluid hyperthermia treatment. Sci. Rep. 2021, 11, 3286, DOI: 10.1038/s41598-021-82095-6 [Crossref], [PubMed], [CAS], Google Scholar

29. Zahedi, M. G.; Lorenzo, D.; Brescia, R.; Ruffilli, R.; Liakos, I.; Pellegrino, T.; Athanassiou, A.; Fragouli, D. Magnetic-Field-Induced Formation of Superparamagnetic Microwires in Suspension. J. Phys. Chem. C 2014, 118, 28220-28226, DOI: 10.1021/jp507951f [ACS Full Text ], [CAS], Google Scholar

30. Andreu, I.; Natividad, E.; Solozábal, L.; Roubeau, O. Nano-objects for Addressing the Control of Nanoparticle Arrangement and Performance in Magnetic Hyperthermia. ACS Nano 2015, 9, 1408-1419, PMID: 25658023 DOI: 10.1021/nn505781f [ACS Full Text], [CAS], Google $\underline{\text { Scholar }}$

31. Lartigue, L.; Hugounenq, P.; Alloyeau, D.; Clarke, S. P.; Lévy, M.; Bacri, J.-C.; Bazzi, R.; Brougham, D. F.; Wilhelm, C.; Gazeau, F. Cooperative Organization in Iron Oxide Multi-Core Nanoparticles Potentiates Their Efficiency as Heating Mediators and MRI Contrast Agents. 
ACS Nano 2012, 6, 10935-10949, PMID: 23167525 DOI: 10.1021/nn304477s [ACS Full Text], [CAS], Google Scholar

32. Blanco-Andujar, C.; Ortega, D.; Southern, P.; Pankhurst, Q. A.; Thanh, N. T. K. High performance multi-core iron oxide nanoparticles for magnetic hyperthermia: microwave synthesis, and the role of core-to-core interactions. Nanoscale 2015, 7, 1768-1775, DOI: 10.1039/c4nr06239f [Crossref], [PubMed], [CAS], Google Scholar

33. Toulemon, D.; Rastei, M. V.; Schmool, D.; Garitaonandia, J. S.; Lezama, L.; Cattoën, X.; BéginColin, S.; Pichon, B. P. Enhanced Collective Magnetic Properties Induced by the Controlled Assembly of Iron Oxide Nanoparticles in Chains. Adv. Funct. Mater. 2016, 26, 24542462, DOI: 10.1002/adfm.201505086 [Crossref], [CAS], Google Scholar

34. Bender, P.; Honecker, D.; Fernández Barquín, L. Supraferromagnetic correlations in clusters of magnetic nanoflowers. Appl. Phys. Lett. 2019, 115, 132406, DOI: 10.1063/1.5121234 [Crossref], [CAS], Google Scholar

35. Price, P. M.; Mahmoud, W. E.; Al-Ghamdi, A. A.; Bronstein, L. M. Magnetic Drug Delivery: Where the Field Is Going. Front. Chem. 2018, 6, 619, DOI: 10.3389/fchem.2018.00619 [Crossref], [PubMed], [CAS], Google Scholar

36. Stolarczyk, J. K.; Deak, A.; Brougham, D. F. Nanoparticle Clusters: Assembly and Control Over Internal Order, Current Capabilities, and Future Potential. Adv. Mater. 2016, 28, 54005424, DOI: 10.1002/adma.201505350 [Crossref], [PubMed], [CAS], Google Scholar

37. Antone, A. J.; Sun, Z.; Bao, Y. Preparation and Application of Iron Oxide Nanoclusters. Magnetochemistry 2019, 5, 45, DOI: 10.3390/magnetochemistry5030045 [Crossref], [CAS], Google Scholar

38. Gutiérrez, L.; Costo, R.; Grüttner, C.; Westphal, F.; Gehrke, N.; Heinke, D.; Fornara, A.; Pankhurst, Q. A.; Johansson, C.; Veintemillas-Verdaguer, S.; Morales, M. P. Synthesis methods to prepare single- and multi-core iron oxide nanoparticles for biomedical applications. Dalton Trans. 2015, 44, 2943- 2952, DOI: 10.1039/c4dt03013c [Crossref], [PubMed], [CAS], Google Scholar

39. Caruntu, D.; Caruntu, G.; Chen, Y.; O’Connor, C. J.; Goloverda, G.; Kolesnichenko, V. L. Synthesis of Variable-Sized Nanocrystals of Fe3O4 with High Surface Reactivity. Chem. Mater. 2004, 16, 5527- 5534, DOI: 10.1021/cm0487977 [ACS Full Text], [CAS], Google Scholar

40. Cheng, C.; Xu, F.; Gu, H. Facile synthesis and morphology evolution of magnetic iron oxide nanoparticles in different polyol processes. New J. Chem. 2011, 35, 1072-1079, DOI: 10.1039/c0nj00986e [Crossref], [CAS], Google Scholar

41. Deng, H.; Li, X.; Peng, Q.; Wang, X.; Chen, J.; Li, Y. Monodisperse Magnetic Single-Crystal Ferrite Microspheres. Angew. Chem., Int. Ed. 2005, 44, 2782- 2785, DOI: 10.1002/anie.200462551 [Crossref], [PubMed], [CAS], Google Scholar

42. Iacovita, C.; Florea, A.; Dudric, R.; Pall, E.; Moldovan, A.; Tetean, R.; Stiufiuc, R.; Lucaciu, C. Small versus Large Iron Oxide Magnetic Nanoparticles: Hyperthermia and Cell Uptake Properties. Molecules 2016, 21, 1357, DOI: 10.3390/molecules21101357 [Crossref], [CAS], Google Scholar

43. Sakellari, D.; Brintakis, K.; Kostopoulou, A.; Myrovali, E.; Simeonidis, K.; Lappas, A.; Angelakeris, M. Ferrimagnetic nanocrystal assemblies as versatile magnetic particle hyperthermia mediators. Mater. Sci. Eng., C 2016, 58, 187- 193, DOI: 10.1016/j.msec.2015.08.023 [Crossref], [PubMed], [CAS], Google Scholar

44. Hugounenq, P.; Levy, M.; Alloyeau, D.; Lartigue, L.; Dubois, E.; Cabuil, V.; Ricolleau, C.; Roux, S.; Wilhelm, C.; Gazeau, F.; Bazzi, R. Iron Oxide Monocrystalline Nanoflowers for Highly Efficient Magnetic Hyperthermia. J. Phys. Chem. C 2012, 116, 15702-15712, DOI: 10.1021/jp3025478 [ACS Full Text ], [CAS], Google Scholar

45. Gavilán, H.; Sánchez, E. H.; Brollo, M. E. F.; Asín, L.; Moerner, K. K.; Frandsen, C.; Lázaro, F. J.; Serna, C. J.; Veintemillas-Verdaguer, S.; Morales, M. P.; Gutiérrez, L. Formation Mechanism of Maghemite Nanoflowers Synthesized by a Polyol-Mediated Process. ACS Omega 2017, 2, 7172- 7184, DOI: 10.1021/acsomega.7b00975 [ACS Full Text ], [CAS], Google Scholar 
46. Reddy, L. H.; Arias, J. L.; Nicolas, J.; Couvreur, P. Magnetic Nanoparticles: Design and Characterization, Toxicity and Biocompatibility, Pharmaceutical and Biomedical Applications. Chem. Rev. 2012, 112, 5818- 5878, PMID: 23043508 DOI: 10.1021/cr300068p [ACS Full Text ], [CAS], Google Scholar

47. Hemery, G.; Keyes, A. C.; Garaio, E.; Rodrigo, I.; Garcia, J. A.; Plazaola, F.; Garanger, E.; Sandre, O. Tuning Sizes, Morphologies, and Magnetic Properties of Monocore Versus Multicore Iron Oxide Nanoparticles through the Controlled Addition of Water in the Polyol Synthesis. Inorg. Chem. 2017, 56, 8232-8243, PMID: 28671822 DOI: 10.1021/acs.inorgchem.7b00956 [ACS Full Text ], [CAS], Google Scholar

48. Iacovita, C.; Florea, A.; Scorus, L.; Pall, E.; Dudric, R.; Moldovan, A. I.; Stiufiuc, R.; Tetean, R.; Lucaciu, C. M. Hyperthermia, Cytotoxicity, and Cellular Uptake Properties of Manganese and Zinc Ferrite Magnetic Nanoparticles Synthesized by a Polyol-Mediated Process. Nanomaterials 2019, 9, 1489, DOI: 10.3390/nano9101489 [Crossref], [CAS], Google Scholar

49. Hachani, R.; Lowdell, M.; Birchall, M.; Hervault, A.; Mertz, D.; Begin-Colin, S.; Thanh, N. T. K. Polyol synthesis, functionalisation, and biocompatibility studies of superparamagnetic iron oxide nanoparticles as potential MRI contrast agents. Nanoscale 2016, 8, 3278-3287, DOI: 10.1039/c5nr03867g [Crossref], [PubMed], [CAS], Google Scholar

50. Iacovita, C.; Fizeşan, I.; Pop, A.; Scorus, L.; Dudric, R.; Stiufiuc, G.; Vedeanu, N.; Tetean, R.; Loghin, F.; Stiufiuc, R.; Lucaciu, C. M. Vitro Intracellular Hyperthermia of Iron Oxide Magnetic Nanoparticles, Synthesized at High Temperature by a Polyol Process. Pharmaceutics 2020, 12, 424, DOI: 10.3390/pharmaceutics12050424 [Crossref], [CAS], Google Scholar

51. Saari, M. M.; Sakai, K.; Kiwa, T.; Sasayama, T.; Yoshida, T.; Tsukada, K. Characterization of the magnetic moment distribution in low-concentration solutions of iron oxide nanoparticles by a high-Tc superconducting quantum interference device magnetometer. J. Appl. Phys. 2015, 117, 17B321, DOI: 10.1063/1.4919043 [Crossref], Google Scholar

52. Hu, J.; Lo, I.; Chen, G. Comparative study of various magnetic nanoparticles for $\mathrm{Cr}(\mathrm{VI})$ removal. Sep. Purif. Technol. 2007, 56, 249-256, DOI: 10.1016/j.seppur.2007.02.009 [Crossref], [CAS], Google Scholar

53. Kazakova, O.; Puttock, R.; Barton, C.; Corte-León, H.; Jaafar, M.; Neu, V.; Asenjo, A. Frontiers of magnetic force microscopy. J. Appl. Phys. 2019, 125, 060901, DOI: 10.1063/1.5050712 [Crossref], [CAS], Google Scholar

54. Rastei, M. V.; Meckenstock, R.; Bucher, J. P.; Devaux, E.; Ebbesen, T. Electrochemical growth of Co nanodots on patterned Si substrates. Appl. Phys. Lett. 2004, 85, 2050-2052, DOI: 10.1063/1.1787597 [Crossref], [CAS], Google Scholar

55. Rastei, M. V.; Meckenstock, R.; Bucher, J. P. Nanoscale hysteresis loop of individual Co dots by field-dependent magnetic force microscopy. Appl. Phys. Lett. 2005, 87, 222505, DOI: 10.1063/1.2138349 [Crossref], [CAS], Google Scholar

56. Jaafar, M.; Yanes, R.; Perez de Lara, D.; Chubykalo-Fesenko, O.; Asenjo, A.; Gonzalez, E. M.; Anguita, J. V.; Vazquez, M.; Vicent, J. L. Control of the chirality and polarity of magnetic vortices in triangular nanodots. Phys. Rev. B: Condens. Matter Mater. Phys. 2010, 81, 054439, DOI: 10.1103/physrevb.81.054439 [Crossref], [CAS], Google Scholar

57. Moya, C.; Iglesias-Freire, Ó.; Batlle, X.; Labarta, A.; Asenjo, A. Superparamagnetic versus blocked states in aggregates of Fe3-xO4 nanoparticles studied by MFM. Nanoscale 2015, 7, 17764- 17770, DOI: 10.1039/c5nr04424c [Crossref], [PubMed], [CAS], Google Scholar

58. Sievers, S.; Braun, K.-F.; Eberbeck, D.; Gustafsson, S.; Olsson, E.; Schumacher, H. W.; Siegner, U. Quantitative Measurement of the Magnetic Moment of Individual Magnetic Nanoparticles by Magnetic Force Microscopy. Small 2012, 8, 2675-2679, DOI: 10.1002/smll.201200420 [Crossref], [PubMed], [CAS], Google Scholar

59. Schreiber, S.; Savla, M.; Pelekhov, D. V.; Iscru, D. F.; Selcu, C.; Hammel, P. C.; Agarwal, G. Magnetic Force Microscopy of Superparamagnetic Nanoparticles. Small 2008, 4, 270278, DOI: 10.1002/smll.200700116 [Crossref], [PubMed], [CAS], Google Scholar 
60. Fuhrmann, M.; Musyanovych, A.; Thoelen, R.; von Bomhard, S.; Möbius, H. Magnetic Imaging of Encapsulated Superparamagnetic Nanoparticles by Data Fusion of Magnetic Force Microscopy and Atomic Force Microscopy Signals for Correction of Topographic Crosstalk. Nanomaterials 2020, 10, 2486, DOI: 10.3390/nano10122486 [Crossref], [CAS], Google Scholar

61. Angeloni, L.; Passeri, D.; Scaramuzzo, F. A.; Schiavi, P. G.; Pagnanelli, F.; Rossi, M. Magnetic force microscopy characterization of core-shell cobalt-oxide/hydroxide nanoparticles. J. Magn. Magn. Mater. 2020, 516, 167299, DOI: 10.1016/j.jmmm.2020.167299 [Crossref], [CAS], Google Scholar

62. Rastei, M. V.; Colis, S.; Bucher, J. P. Growth control of homogeneous pulsed electrodeposited Co thin films on n-doped Si(111) substrates. Chem. Phys. Lett. 2006, 417, 217-221, DOI: 10.1016/j.cplett.2005.09.122 [Crossref], [CAS], Google Scholar

63. Iacovita, C.; Hurst, J.; Manfredi, G.; Hervieux, P. A.; Donnio, B.; Gallani, J. L.; Rastei, M. V. Magnetic force fields of isolated small nanoparticle clusters. Nanoscale 2020, 12, 18421851, DOI: 10.1039/c9nr08634j [Crossref], [PubMed], [CAS], Google Scholar

64. Rastei, M. V.; Pierron-Bohnes, V.; Toulemon, D.; Bouillet, C.; Kákay, A.; Hertel, R.; Tetsi, E.; Begin-Colin, S.; Pichon, B. P. Defect-Driven Magnetization Configuration of Isolated Linear Assemblies of Iron Oxide Nanoparticles. Adv. Funct. Mater. 2019, 29, 1903927, DOI: 10.1002/adfm.201903927 [Crossref], [CAS], Google Scholar

65. Angeloni, L.; Passeri, D.; Corsetti, S.; Peddis, D.; Mantovani, D.; Rossi, M. Single nanoparticles magnetization curves by controlled tip magnetization magnetic force microscopy. Nanoscale 2017, 9, 18000-18011, DOI: 10.1039/c7nr05742c [Crossref], [PubMed], [CAS], Google Scholar

66. Jaafar, M.; Serrano-Ramón, L.; Iglesias-Freire, O.; Fernández-Pacheco, A.; Ibarra, M. R.; De Teresa, J. M.; Asenjo, A. Hysteresis loops of individual Co nanostripes measured by magnetic force microscopy. Nanoscale Res. Lett. 2011, 6, 407, DOI: 10.1186/1556-276x-6-407 [Crossref], [PubMed], [CAS], Google Scholar

67. Sasaki, S. Radial Distribution of Electron Density in Magnetite, Fe304. Acta Crystallogr., Sect. B: Struct. Sci. 1997, 53, 762- 766, DOI: 10.1107/s0108768197007842 [Crossref], [CAS], Google Scholar

68. Baaziz, W.; Pichon, B. P.; Fleutot, S.; Liu, Y.; Lefevre, C.; Greneche, J.-M.; Toumi, M.; Mhiri, T.; Begin-Colin, S. Magnetic Iron Oxide Nanoparticles: Reproducible Tuning of the Size and Nanosized-Dependent Composition, Defects, and Spin Canting. J. Phys. Chem. C 2014, 118, 3795- 3810, DOI: 10.1021/jp411481p [ACS Full Text ], [CAS], Google Scholar

69. Barbara, P.; Simona, K.; Alice, R.; Daniel, N.; Jana, V. Magnetic Spinels: Synthesis, Properties and Applications; Mohindar., Seehra, Ed.; IntechOpen, 2017; Chapter 1.Google Scholar

70. Angeloni, L.; Passeri, D.; Reggente, M.; Mantovani, D.; Rossi, M. Removal of electrostatic artifacts in magnetic force microscopy by controlled magnetization of the tip: application to superparamagnetic nanoparticles. Sci. Rep. 2016, 6, 26293, DOI: 10.1038/srep26293 [Crossref], [PubMed], [CAS], Google Scholar

71. Jaafar, M.; Iglesias-Freire, O.; Serrano-Ramón, L.; Ibarra, M. R.; de Teresa, J. M.; Asenjo, A. Distinguishing magnetic and electrostatic interactions by a Kelvin probe force microscopymagnetic force microscopy combination. Beilstein J. Nanotechnol. 2011, 2, 552-560, DOI: 10.3762/bjnano.2.59 [Crossref], [PubMed], [CAS], Google Scholar

72. Krivcov, A.; Junkers, T.; Möbius, H. Understanding electrostatic and magnetic forces in magnetic force microscopy: towards single superparamagnetic nanoparticle resolution. $J$. Phys. Commun. 2018, 2, 075019, DOI: 10.1088/2399-6528/aad3a4 [Crossref], [CAS], Google $\underline{\text { Scholar }}$

73. Neves, C. S.; Quaresma, P.; Baptista, P. V.; Carvalho, P. A.; Araújo, J. P.; Pereira, E.; Eaton, P. New insights into the use of magnetic force microscopy to discriminate between magnetic and nonmagnetic nanoparticles. Nanotechnology 2010, 21, 305706, DOI: 10.1088/09574484/21/30/305706 [Crossref], [PubMed], [CAS], Google Scholar 
74. Garcia, J. M.; Thiaville, A.; Miltat, J.; Kirk, K. J.; Chapman, J. N. MFM imaging of patterned permalloy elements under an external applied field. J. Magn. Magn. Mater. 2002, 242-245, 1267- 1269, Proceedings of the Joint European Magnetic Symposia (JEMS'01) DOI: 10.1016/S0304-8853(01)01027-7 [Crossref], [CAS], Google Scholar

75. Zhu, X.; Grütter, P.; Metlushko, V.; Ilic, B. Systematic study of magnetic tip induced magnetization reversal of e-beam patterned permalloy particles. J. Appl. Phys. 2002, 91, 7340- 7342, DOI: 10.1063/1.1452683 [Crossref], [CAS], Google Scholar

76. Guhr, I. L.; Dijken, S. v.; Malinowski, G.; Fischer, P.; Springer, F.; Hellwig, O.; Albrecht, M. Magnetization reversal in exchange biased nanocap arrays. J. Phys. D: Appl. Phys. 2007, 40, 3005- 3010, DOI: 10.1088/0022-3727/40/10/s02 [Crossref], [CAS], Google Scholar

77. Mironov, V. L.; Gribkov, B. A.; Vdovichev, S. N.; Gusev, S. A.; Fraerman, A. A.; Ermolaeva, O. L.; Shubin, A. B.; Alexeev, A. M.; Zhdan, P. A.; Binns, C. Magnetic force microscope tipinduced remagnetization of CoPt nanodisks with perpendicular anisotropy. J. Appl. Phys. 2009, 106, 053911, DOI: 10.1063/1.3202354 [Crossref], [CAS], Google Scholar

78. Puwenberg, N.; Reiche, C. F.; Streubel, R.; Khan, M.; Mukherjee, D.; Soldatov, I. V.; Melzer, M.; Schmidt, O. G.; Büchner, B.; Mühl, T. Magnetization reversal and local switching fields of ferromagnetic Co/Pd microtubes with radial magnetization. Phys. Rev. B 2019, 99, 094438, DOI: 10.1103/physrevb.99.094438 [Crossref], [CAS], Google Scholar

79. van Schendel, P. J. A.; Hug, H. J.; Stiefel, B.; Martin, S.; Güntherodt, H.-J. A method for the calibration of magnetic force microscopy tips. J. Appl. Phys. 2000, 88, 435-445, DOI: 10.1063/1.373678 [Crossref], [CAS], Google Scholar

80. Streblechenko, D. G.; Scheinfein, M. R.; Mankos, M.; Babcock, K. Quantitative magnetometry using electron holography: field profiles near magnetic force microscope tips. IEEE Trans. Magn. 1996, 32, 4124-4129, DOI: 10.1109/20.539316 [Crossref], Google Scholar

81. Abes, M.; Rastei, M. V.; Venuat, J.; Carvalho, A.; Boukari, S.; Beaurepaire, E.; Panissod, P.; Dinia, A.; Bucher, J. P.; Pierron-Bohnes, V. Magnetic switching field distribution of patterned CoPt dots. J. Appl. Phys. 2009, 105, 113916, DOI: 10.1063/1.3117514 [Crossref], [CAS], Google Scholar

82. de la Presa, P.; Luengo, Y.; Velasco, V.; Morales, M. P.; Iglesias, M.; Veintemillas-Verdaguer, S.; Crespo, P.; Hernando, A. Particle Interactions in Liquid Magnetic Colloids by Zero Field Cooled Measurements: Effects on Heating Efficiency. J. Phys. Chem. C 2015, 119, 1102211030, DOI: 10.1021/jp5115515 [ACS Full Text ], [CAS], Google Scholar 